\title{
Maurice Whitehead
}

English Jesuit Education: Expulsion, Suppression, Survival and Restoration, 1762-1803. Farnham: Ashgate, 2013. Pp. xviii + 266. Hb, \$124.95.

Transnational approaches have recently become increasingly prominent in the history of education. This trend is itself a counter-tendency to the widespread predilection of historians of education to focus more narrowly on the individual case in a particular local and national context. Over the past decade, it has become more common to establish a broader framework, and to highlight issues in their geographical, social, and political settings that run across the boundaries of nation-states. Such work has also created methodological challenges, particularly in the examinations of archival material held in different centers, often in different conditions, and in a number of languages.

Maurice Whitehead's book is an excellent example of this emergent historiographical trend, and of the benefits it can yield when combined with the more established qualities of rigorous historical research. It tells the story of English Jesuit education from its origins, beginning with the CounterReformation and the founding of the order, developing through the Catholic Enlightenment, and finally reaching its culmination with the establishment of Stonyhurst College in early nineteenth-century England: according to the author, "one of the most extraordinary phenomena in British educational history" (179). The particular focus of the book is on the period from 1762 to 1803 , but it is well framed in this longer-term context. In some ways it provides a traditional narrative, in that the history of education has so often produced heroic accounts of triumph over adversity. In this case, the familiar style resists the common temptation to idealize its heroes. It is scrupulously researched, and observes complexity and nuance at every turn.

Whitehead's book stretches across nations and continents, as well as over time. Its principal base is continental Europe, and especially the principality of Liège. Yet it documents the connections and networks that helped it to persevere, often as an underground organization persecuted by the authorities. The English College is described as constituting, by the late eighteenth century, "a truly international educational institution, with students from England, Ireland, the United States of America, the Caribbean, the Low Countries, France and Spain" (161). Whitehead highlights, for example, the trails between different locations across Europe, depicted in the detailed and helpful maps that are provided. It provides an interesting discussion of links with White Russia and the efforts to maintain and develop contacts. Above all, the volume reveals the connections with England, often fraught with danger but operating in different directions to support an international network that tended to be a widely spread diaspora of refugees. 
The volume is often preoccupied, necessarily, with detailed documentation of the political maneuvers that affected the Jesuit educational movement. Chapter three, for example, is taken up with the complex series of European events in the 1750 s and 1760 s that combined to undermine the position of the Society of Jesus. Chapter five is concerned with the suppression of the Jesuits in the 1770 s, first in the Austrian Netherlands in general and then the effects on the English Colleges at Bruges in 1773, which led to the creation of the English Academy in Liège. This is important in itself, but it is when the work examines the distinctive educational characteristics of these institutions that it really conveys the full significance of the movement. This becomes evident in chapter two, which deals with the development of St. Omers from its establishment under Robert Persons in 1593 until the crisis that overtook it in 1762. It examines the spiritual and pedagogical aspects of the college and the nature of the curriculum, and points out tellingly that "[i]n an age in which no nation state yet possessed a national curriculum, the Society of Jesus had, by 1700, been successfully operating an international curriculum for over a century" (37). At the same time, it highlights the growing fossilization and conservatism of the curriculum under the Ratio studiorum, which had originally located the Society of Jesus at the heart of Renaissance educational thought and pedagogical practice, but became unable to reorient itself to the demands of eighteenthcentury society.

Chapter six, on the English Academy in Liège under John Howard from 1773 to 1775 , deals in depth with these changes. In the context of an institution that was able to enroll students of all ages from many different countries, "[f]or the first time for nearly 200 years, they were free to allow the primary and secondary level classical traditions of St Omers, Watten and Bruges to intermingle with the tertiary level scientific and philosophical traditions of Liège, potentially providing a new type of curriculum" (127). This was notably influenced by the convent school for girls in Liège under Mary Christine Dennett, who later migrated to England to establish a school at New Hall in Chelmsford, Essex. Whitehead observes that the role of Dennett's convent school constitutes "a rare and very early example of female education influencing the curriculum provided for young men" (129). This chapter also suggests connections with the curriculum of Warrington Academy in England, influenced by Joseph Priestley, and the development of a library culture at the English Academy which established it as an "intellectual powerhouse" (137). Such fascinating developments might well be taken up in further research including, as Whitehead acknowledges, work on the history of the English College in Liège itself.

The nature of the archival research in the book is also worthy of comment. It has clearly benefited greatly from a research grant by the Spencer Foundation 
in Chicago: the money was well spent on visits to relevant libraries and archives in Austria, Belgium, Britain, France, Italy, and the USA. It also owes much to the forensic detective work of the author in establishing the connections between the sources that have been located in these different centers. This includes the discovery of the manuscript catalog of the Great Library of the English Academy at Liège in the Royal Library in Brussels, and the records of students and finances discussed in a superb extended footnote on page 161.

Overall, this is an excellent and much-needed contribution to the international literature on the history of education, well produced in both text and illustrations as well as in its general design. It combines the best attributes of traditional historical scholarship with the ambitious aspirations of new developments in historical research in education, while also adding greatly to our historical understanding of the Jesuit movement as a whole.

Gary McCulloch

Institute of Education, University of London

G.McCulloch@ioe.ac.uk 